\title{
Analyst
}

CORRECTION

View Article Online

View Journal I View Issue

\section{Correction: Photoinduced electron transfer as a design concept for luminescent redox indicators}

Cite this: Analyst, 2017, 142, 676

DOI: 10.1039/c7an90008b

rsc.li/analyst
David C. Magri

Correction for 'Photoinduced electron transfer as a design concept for luminescent redox indicators' by David C. Magri, Analyst, 2015, 140, 7487-7495.

In the original manuscript, Fig. 3 contained an error. The correct figure and caption are as follows:
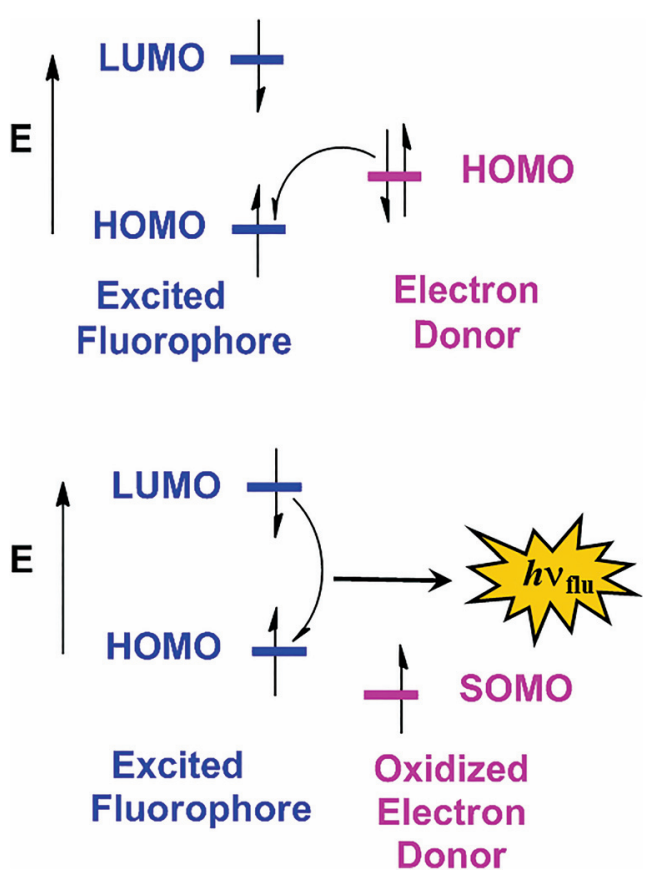

Fig. 3 The 'lumophore-spacer-electron-donor' molecular orbital energy diagrams illustrating the two thermodynamic situations. (top) PET from the electron donor to the excited state lumophore and (bottom) luminescence from the excited state lumophore after oxidation of the electron donor.

The Royal Society of Chemistry apologises for these errors and any consequent inconvenience to authors and readers. 